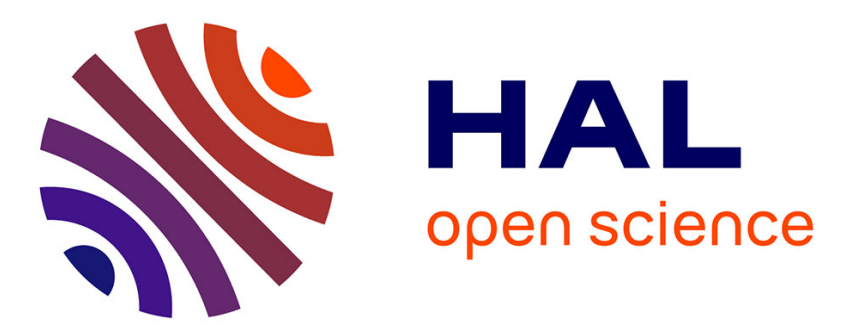

\title{
Establishing Profiles for Systems Engineering Standards: A Great Help for Companies to Manage Their Processes
}

Rui Xue, Claude Baron, Philippe Esteban, Qiang Zhang

\section{To cite this version:}

Rui Xue, Claude Baron, Philippe Esteban, Qiang Zhang. Establishing Profiles for Systems Engineering Standards: A Great Help for Companies to Manage Their Processes. 2014 CAETS International Conference on Engineering Science and Technology, Jun 2014, Beijing, China. 10.15302/J-FEM2014036 . hal-01284563

\section{HAL Id: hal-01284563 https://hal.science/hal-01284563}

Submitted on 15 Mar 2016

HAL is a multi-disciplinary open access archive for the deposit and dissemination of scientific research documents, whether they are published or not. The documents may come from teaching and research institutions in France or abroad, or from public or private research centers.
L'archive ouverte pluridisciplinaire HAL, est destinée au dépôt et à la diffusion de documents scientifiques de niveau recherche, publiés ou non, émanant des établissements d'enseignement et de recherche français ou étrangers, des laboratoires publics ou privés. 


\title{
Establishing profiles for Systems Engineering Standards: a Great help for companies to manage their processes
}

\author{
Rui Xue ${ }^{1,2}$, Claude Baron ${ }^{1,2}$, Philippe Esteban ${ }^{1,3}$, Qiang ZHANG $^{4}$ \\ ${ }_{1}$ CNRS, LAAS, 7 avenue du colonel Roche, F-31400 Toulouse, France \\ 2 Univ de Toulouse, INSA, LAAS, F-31400 Toulouse, France \\ ${ }_{3}$ Univ de Toulouse, Université Paul Sabatier, LAAS, F-31000,Toulouse, France \\ ${ }^{4}$ LPOID,Hefei University of Technology, Hefei, Anhui, 230009, PR China \\ rxue@laas.fr, claude.baron@insa-toulouse.fr, esteban@laas.fr,zhangqiangonline@gmail.com
}

\begin{abstract}
In this paper, we discuss how to establish profiles of Systems Engineering standards for companies.In order todefine anappropriate system engineering standard for a company, this paper presents a detailed comparison between the current releases of the main Systems Engineering standards(ANSI/EIA-632, ISO/IEC-15288 and IEEE1220), and explains how to choose the most adapted one according to the company practices. When no standard completely corresponds, the paper suggests and illustrates how to elaborate a tailor-made standard on the basis of specific required characteristics of the companyor of theproject, followinga multi-standard approach, leading to to extend and adapt a standard by importing some elements from another.
\end{abstract}

Keywords: System Engineering; Analysis and Comparison;Sytem Engineering Management, Process;Multistandards approach.

\section{Introduction}

In order to develop systems quickly and efficiently, it is necessary to carefullyimplement System Engineering(SE)standard during the project. Many SE standards have been drawn up in recent years. But the lack of consistency and the existence of conflicts between SE standards make it difficult for project managers and project teams to implement efficient project management (Sharon et al., 2011; Boarder, 1995; Olson and Mozzuchi, 2012). At the same time, the SE standards are frequently being updated; it is thus difficult to adapt the company practices at every revision of the standard, that can be a major one, so that companies are willing to establish their own stable SE policies and processes.

To address these issues,this paper goal is to present an analysis and a detailed comparison between the current releases of SE standardsand to illustrate how to choose a SE standard on the basis of specific criteria. This comparison 
might be useful for an organization establishing its own SE policies and processes by having a resource that describes the strengths and weaknesses of each of the major standards, thus providing a kind of profile for it, pointing out some characteristic features. For this purpose, we explain how and why we selected aSE standard for one ofour research example. To go further, as in our case, the chosen standarddidnot completely satisfy our selection criteria (coverage of the system life cycle, abstraction level, relationships between the processes, and the validationandverification processes), we had to find a way toextend and adapt this standard. This paper thus explains how we considered adapting standards extending one standard with elements from another standard, and presents the resulting multi-standard reference.

The paper is organized as follows: Section 2 introduces and analyzes the evolution and analysis of threemain systems engineering standards. Section Erreur ! Source du renvoi introuvable. compares thesestandards and illustrates how to make a choice between them according to specific criteria; it also suggests extensions for adapting a standard with elements from other standards. Section4summarizes and discusses the different contributions of this paper.

\section{Evolution and analysis of main systems engineering standards}

\subsection{History and evolutions of systems engineering standards}

The first SE standard appeared in 1969. Over the years, many SE standardshave been derived from it. Figure 1 shows the lines of evolution and the relationships between thesome SEstandards (Sheard and Lake, 1998; Annalisa, 2000). Reality is much more complex. Indeed, a number of SE standards have been released, some of theminfluenced by other available standards, particularly those in the software world. Some standards have been heavily publicized whileothers were less well known, or did not achieve industry consensus (Sheard and Lake, 1998).The first standard, MIL-STD-499, was published to establish systems engineering management techniques in 1969. The goal was to provide a set of criteria to serve as a guide to contractors preparing systems engineering proposals and validating the contractor's systems engineering management capability. The scope and requirements of systems engineering were defined in terms of what should be done: the systems engineering activities to be managed were defined but not how to manage them.In 1994, the USA DoD decided to stop producing standards anymore, but two organizations have launched this time two standards emerged: The EIA and IEEE. The EIA developed the version 1994 of the ANSI/EIA 632 (EIA/IS-632:1994) standard which was only a draft, this version has been submitted for review and more than 700 comments were received that force editorship EIA to update the document; the revised version has been released as version 1 at the end of 1998. The first edition of ISO 15288 was issued on 1 November 2002. In 
2004 this standard was adopted as IEEE 15288. ISO/IEC 15288 has been updated again in February 2008by Joint Technical Committee ISO/IEC JTC 1, Information technology, Subcommittee SC 7, Systems and software engineering. In 1994, IEEE developed its SE standard: IEEE-1220:1994.

\subsection{Comparison of systems engineering standards}

As shown in Figure 1, from this standard the three current standardswere later derived: ANSI/EIA-632:1998, ISO/IEC-15288:2008 and IEEE-1220:2005.The three SE standards describe best systems engineering practices. They have been approved through a defined industry-approval process such as those established by ANSI. US military standards initially supported contracts, to help the government acquiring quality products or ensuring the utilization of consistent processes by contractors. In general, commercial standards (ANSI/EIA-632:1998 or IEEE-1220:2005) are not imposed on contracts and their use is voluntary. Standards say what should be done, but try not to say how to do it. They therefore focus on processes and their related activities and tasks on requirements (the 'what'), rather than on methods and tools (the 'how'). They may implicitly evokea life cycle to provide a context for their recommendation, although most specify their suggested life cycles as 'typical' or 'example'.

Obviously there are many differences between the three standards. For the general comparison of the three standards, the criteria that we chose to compare the three current standards are the same as theirs: systems life cycle,scope\&abstractionlevelandfocal point.

Table 1Comparison of the three standards

\begin{tabular}{|c|c|c|c|}
\hline & ANSI/EIA-632:1998 & ISO/IEC-15288:2008 & IEEE-1220:2005 \\
\hline System life cycle & 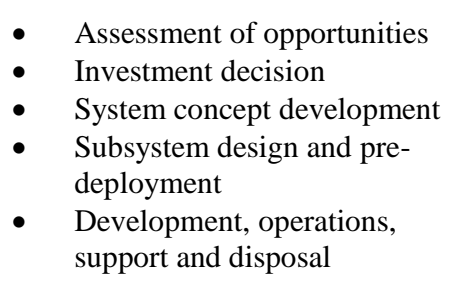 & $\begin{array}{ll}\text { - } & \text { Conception } \\
\text { - } & \text { Development } \\
\text { - } & \text { Production } \\
\text { - } & \text { Utilization } \\
\text { - } & \text { Support } \\
\text { - } & \text { Retirement }\end{array}$ & $\begin{array}{ll}\text { - } & \text { System definition } \\
\text { - } & \text { Preliminary design } \\
\text { - } & \text { Detailed design } \\
\text { - } & \text { FAIT (Fabrication, Assembly, } \\
& \text { Integration and Test) } \\
\text { - } & \text { Production } \\
\text { - } & \text { Support }\end{array}$ \\
\hline Scope & 13 processes, 33 requirements & 25 processes & $\begin{array}{c}14 \text { requirements, } 6 \text { stages, } 8 \text { sub- } \\
\text { processes }\end{array}$ \\
\hline Abstraction level & Medium & Highest & Lowest \\
\hline Focal point & Enterprise-based systems & $\begin{array}{l}\text { Product-oriented sys- } \\
\text { tems }\end{array}$ & $\begin{array}{l}\text { Engineering activities necessary to } \\
\text { guide product development }\end{array}$ \\
\hline
\end{tabular}


(1)Systems life cycle

The system life cycle on which the ANSI/EIA-632:1998 standard reliesconcernsthe implement of the requirements of the standards within a defined engineering life cycle, which can be applied in any enterprise-based life cycle stage to engineer or reengineer a system. As shown in Figure 2, the ANSI/EIA-632:1998 standard distinguishes between the assessment of opportunities stage and the investment decision stage.However, the ISO/IEC-15288:2008 and IEEE-1220:2005 standards both describe the system life cycle from a systems engineering viewpoint.The ISO/IEC15288:2008standard focuses on a set of generic processes applied as appropriate to accomplish the purposes of any one of the phases of a system's life cycle, covering the system life cycle as six stages: conception, development, production, utilization, support and retirement (see Figure 2).Although the IEEE-1220:2005 standard also covers the development stage of the system life cycle, it pays more attention on the enterprise (large organization).It divides the system life cycle into 6 stages: system definition, preliminary design, detailed design and FAIT, production and support (see Figure 2).

(2) Scope\&abstractionlevel

The ANSI/EIA-632:1998 standard describes the system life cycle at a requirement description level, and defines 13 processes and 33 requirements. And the ISO/IEC-15288:2008 standarddescribes the whole processes at the highest detailed level; it defines 25 processes and furtherdescribestheir detailed activities, tasks and outcomes. The IEEE1220:2005 standard focuses more on the development stage, so it defines purpose, tasks and outcomes in more detail than the ANSI/EIA-632:1998 standard.

(3) Focal point

The three standards also vary their focus in a way that mirrors the change in industry outlook (Sheard and Lake, 1998). In short, the ANSI/EIA-632:1998 standard is more suitable for engineering enterprise-based systems; it focuses more on the technical management, validation and verification aspects. The ISO/IEC-15288:2008 standard is more suitable for engineering complex systems, especially projects that cover an entire system life cycle. The IEEE1220:2005 standard is more suitable for smaller systems and focuses on the development stage rather than the system life cycle or the technical management aspects.

In this Section, we presented an overall analysis of the three current SE standards. We pointed out their similarities and differences on the basis of three general criteria: systems life cycle,scope\&abstractionlevelandfocal point.Wereached certain conclusions:the ANSI/EIA-632:1998 standard does not mention the retirement stage, and onlyconsiders some aspects of the context of support and maintenance; it does not cover all of the system life cycle. 
The ISO/IEC-15288:2008 standard focuses more on the system life cycle; it provides fewer criteria about the assessment of the opportunities and the investment decision. The IEEE-1220:2005standard focuses more on the development stage; it does not have wide application as it is too detailed to provide the flexibility for easy application.

\section{Customized standard: a multi-standard approach}

As analyzed in the previous section,three SE standards describe best systems engineering practices, and provide the reference framework for projects. However, nowadays, project management is becoming more and more complex, with the increasing number of partners, the heterogeneity of contributions and the complexity of the systems(Boarder, 1995; Rocardo, 2005; Sahraoui, 2006). Moreover, different projects involve with particular requirements. Therefore, theremay be nostandard fully satisfies all project requirements. We consider the option of extending a standard with another one, to obtain a multi-standard reference, thereby realizing the customized standard. In order to achieve the purpose above, we introduce how to select a Systems Engineering standard by our research example (DECWAYS).

\subsection{Research objectives}

This research example (DECWAYS) addresses collaborative engineering questions, and itsmain goal is to improve and facilitate coordination between developers and project managers, providing them with a method and a tool to choose a SE standard according to their own requirements.In order to achieve this goal, it is necessary to combine SE standards with project management standards.The selected SE standard had to satisfy several specific criteria. Our needs are listed below:

1) We need the standard to cover the entire system life cycle, from conception to retirement.

2) The level of complexity in simulating project progress depends on the level of abstraction of the standard; the standard should therefore offer a medium level of abstraction.

3) With increasing project complexity, $\mathrm{V} \& \mathrm{~V}$ (validation and verification) becomes more and more important; the standard should provide a detailed view of the $\mathrm{V} \& \mathrm{~V}$ processes. 
4) The object of our research was tofind the best tools for coordinating processes and simulating project progress; as a result, the relationships between processes are key points for the comparison of standards.

\subsection{Our proposal to use a multi-standard approach}

\subsubsection{Constructing comparison standards}

Based on these requirements mentioned in the Section 3.1, wefirstly derive criteria for refining the comparison of standards. Theextent of coverage and the level of abstraction criteria have already been discussed in Section 2.2. We add three new criteria. The first two are validation and verification, each with their respective level of abstraction. In order to ensure that the simulation of project progress is reliable, we need clearly to know and model the relationships between the processes. It is therefore necessary to study a third criterion, the degree of internal consistency of each standard, to enable an evaluation of the possibilities of cooperation between the processes.

\subsubsection{Choosing the major standard}

According to the comparison standards, the detailed analysis and comparison of the three standards are shown in Table 2.Table 2identifies our justification for the choice of either ANSI/EIA-632:1998 or ISO/IEC-1220:2005 for each criterion, as indicated in the last column. The colored portion of Table 4 indicates which best meets the criteria.Based on the analysis result, we argue that ANSI/EIA-632:1998 is the most appropriatefor our research study.Arguments for choosing ANSI/EIA-632:1998:

a) The most important reason is that our aim is to develop a tool for enterprises to make decisions concerning systems engineering, and the ANSI/EIA-632:1998 standard is based on the enterprise-based system life cycle; the users of the tool are enterprises so the ANSI/EIA-632:1998 is the best choice.

b) It is neither the most nor the least detailed standard for systems engineering, providing each enterprise with the greatest degree of expandabilityand flexibility.

c) For each process, it gives the relationships with the other processes: this is important because the conflict always arises from different processes, and it is easier to simulate the result from the different processes when the relationships between the processes are known.

d) Our object is to help the enterprise/developer decide between many alternatives. So we focus on assessment, opportunities and management. The ANSI/EIA-632:1998 standard considers more processes related to these topics.

e) For our purpose, validation and verification are also important. The credibility of simulation results depends on not only model correctness, but also the accurate problem formulation. Validation and verification tech- 
niques should therefore be employed throughout the life cycle of a simulation study starting with problem formulation and culminating with the presentation of simulation results (Balci, 1994). The processes of validation and verification are defined in more detail in the ANSI/EIA-632:1998 standard.

Table 2Full comparison of standards

\begin{tabular}{|c|c|c|c|c|}
\hline & ANSI/EIA-632:1998 & $\begin{array}{l}\text { ISO/IEC- } \\
15288: 2008\end{array}$ & IEEE-1220:2005 & Argument \\
\hline Scope of standard & $\begin{array}{l}\text { Defines } 5 \text { process groups, a total } \\
\text { of } 33 \text { requirements for } 13 \\
\text { processes, gives tasks and out- } \\
\text { comes for each requirement, gives } \\
\text { some application context and key } \\
\text { concepts }\end{array}$ & $\begin{array}{l}\text { Defines } 3 \text { concept } \\
\text { groups and } 4 \\
\text { process groups, } 25 \\
\text { system life cycle } \\
\text { processes, gives the } \\
\text { purpose, tasks and } \\
\text { outcomes for each } \\
\text { process }\end{array}$ & $\begin{array}{l}\text { Defines } 14 \text { general re- } \\
\text { quirements for developing } \\
\text { a total system, gives } 8 \\
\text { subprocesses for one } \\
\text { systems engineering } \\
\text { process, gives the tasks } \\
\text { and activities for each } \\
\text { subprocess }\end{array}$ & \\
\hline System life cycle & $\begin{array}{ll}\text { - } & \text { Assessment of opportunities } \\
\text { - } & \text { Investment decision } \\
\text { - } & \text { System concept development } \\
\text { - } & \text { Subsystem design and pre- } \\
\text { deployment } \\
\text { - } \\
\text { Development, operations, } \\
\text { support and disposal }\end{array}$ & $\begin{array}{ll}\text { - } & \text { Conception } \\
\text { - } & \text { Development } \\
\text { - } & \text { Production } \\
\text { - } & \text { Utilization } \\
\text { - } & \text { Support } \\
\text { - } & \text { Retirement }\end{array}$ & $\begin{array}{ll}\text { - } & \text { System definition } \\
\text { - } & \text { Preliminary design } \\
\text { - } & \text { Detailed design } \\
\text { - } & \text { FAIT } \\
\text { - } & \text { Production } \\
\text { - } & \text { Support }\end{array}$ & \\
\hline $\begin{array}{l}\text { Abstraction level } \\
\text { of the processes }\end{array}$ & $\begin{array}{l}\text { Lower level than ISO/IEC- } \\
\text { 15288:2008,higher than IEEE- } \\
\text { 1220:2005 }\end{array}$ & Highest level & Lowest level & b \\
\hline Focal point & Enterprise-based systems & $\begin{array}{l}\text { Product-oriented } \\
\text { systems }\end{array}$ & $\begin{array}{l}\text { The engineering activities } \\
\text { necessary to guide prod- } \\
\text { uct development }\end{array}$ & $\mathrm{a}, \mathrm{d}$ \\
\hline Validation & $\begin{array}{l}\text { Gives more details about valida- } \\
\text { tion: requirement validation; } \\
\text { solution representations,end } \\
\text { product validation }\end{array}$ & $\begin{array}{l}\text { Requirement valida- } \\
\text { tion }\end{array}$ & End product validation & $\mathrm{e}$ \\
\hline Verification & $\begin{array}{l}\text { Gives more details about verifica- } \\
\text { tion: design solution verification; } \\
\text { end product verification; enabling } \\
\text { product readiness }\end{array}$ & $\begin{array}{l}\text { Function verifica- } \\
\text { tion }\end{array}$ & Design verification & $\mathrm{e}$ \\
\hline $\begin{array}{l}\text { Internal consis- } \\
\text { tency }\end{array}$ & $\begin{array}{l}\text { Highest, gives the relationship } \\
\text { between the processes, activities }\end{array}$ & $\begin{array}{l}\text { Higher than IEEE- } \\
\text { 1220:2005 }\end{array}$ & Lowest & $\mathrm{c}$, \\
\hline
\end{tabular}

\subsubsection{Adding complementary elements from other standards}

Although the ANSI/EIA-632:1998 is the most appropriateforour research study, we found that there isno standard that fully satisfy all the criteria.We therefore studied the possibility of extending the ANSI/EIA-632:1998 standard by the addition of some elements to better achieve our object. 
In order to cover the entire system life cycle and to enable adaptation to larger scale systems, it is necessary to add some important processes to the ANSI/EIA-632:1998, because they are eitherlacking or are insufficiently detailed. We chose the following processes fromthe ISO/IEC-15288:2008 to complete the ANSI/EIA-632:1998.

a) "Integration process". With the development of science and technology, systems become more and more complex, with the result that subsystems are more numerousthan previously. To minimize the lead time for system development, many processes must be carried out in parallel. At the end of each phase, the outcomes of different groups need to be integrated, and so the integration processitself becomes increasingly important and must therefore be added to the systems engineering process.

b) "Maintenance and disposal process".To complete the system life cycle, the maintenance and disposal processes are also very important;in order to address global competition, many manufacturing companies seek ways to gain competitive advantage with respect to cost, service, quality and on-time delivery.The Proper maintenance can improve the quality, efficiency and effectiveness of production systems, and thus enhance company competitiveness. Many researches(Alsyouf, 2004; PMI, 2013; Rao and Sarda, 2003)studying the domain of the maintenance of system products have concluded that the maintenance process is extremely important for systems engineering processes;yet the maintenance process isnot defined in ANSI/EIA-632:1998.We therefore add the maintenance processinto the systems engineering processes. The purpose of the disposal process is to end the existence of a system entity. To complete a system life cycle, there should be an end phase for the product, which marks not only the end of the old product,but also the beginning of a new product or system.

c) "Human resource". The human aspects of systems engineering are becoming more and more important; the skills of the developer influencethe quality of the system, yet in the ANSI/EIA-632:1998 standard, the processes of the human and training process are not defined. Depending on the roles required to carry out these processes, we propose to add the human resource management process from the ISO/IEC-15288:2008 standard.

d) "Tailoring process". Tailoring is not a requirement for conformance to the standards. In fact, tailoring is not permitted if a claim of "full conformance" is to be made. If, however, "tailored conformance" is permitted, an appropriate process is applied to perform the tailoring. Because of the different requirements, systems and structures, systems engineering also requires a tailoring process. This is defined in the ISO/IEC15288:2008 standard, along with the corresponding tasks and activities, which can also be used for the other standards. For the flexibility of our multi-standard approach, we add the tailoring process to the ANSI/EIA632:1998standard. 


\subsubsection{The resulting systemsengineering processes in our proposal}

The final structureof systems engineering processes is shown in Figure 3; the processes that are underlined are selected from ISO/IEC-15288:2008, the others come from ANSI/EIA-632:1998. At this stage of the study, we obtained a multi-standard SE reference that satisfies general and specific criteria. However, consideringthe processes of this reference and their relationships in detail, it is necessary to verifythe following:

- That the processes extracted from ANSI/EIA-632:1998orISO/IEC-15288:2008 are mutually compatible.

- That the processes extracted from the two standards offer a similar level of abstraction.

- That the processes extracted from ISO/IEC-15288:2008 can be subdivided into the 5 groups of the ANSI/EIA-632:1998 standard.

- That the processes extracted from ANSI/EIA-632:1998 and ISO/IEC-15288:2008share the same vocabulary and that tasks and activities are not duplicated.

\subsection{Risks of a multi-standard approach}

Before using the multi-standard approach we must consider the risks defined above in Section 3.2.4. Firstly, considering the compatibility of processes, there are two points to consider: (1) in the ANSI/EIA-632:1998, there is no process that is identical to any process we selected from the ISO/IEC-15288:2008, which eliminates the principal risk of inconsistency.(2) these processes involve only a few activities. When we execute tasks that correspond to the processes from ISO/IEC-15288:2008, we only need to execute these processes instead of the tasks in the ANSI/EIA632:1998. So we can conclude that the processes concerned are mutually compatible.

The second issueconcerns the abstraction level. Although the abstraction level of the ANSI/EIA-632:1998 standard is higher than that of the ISO/IEC-15288:2008 standard, the processes from the two standards have the same structure. Both standards give the definition, purpose, tasks, activities and the outcomes of each process. So the processes from the two standards can be used in the same way.

The third issue is how to classify the processes from the ISO/IEC-15288:2008 into the five groups of the ANSI/EIA-632:1998. As we showed in Figure 3, the integration process, maintenance process and disposal process are clearly in the product realization group, while the tailoring process is in the technical support group. 
Thefourthissueemphasizesthe definitions used in the three standards. We compared themand found that the brief definitions are identical or similar. For example, in the ANSI/EIA-632:1998, the definition of "process" is that "the process is a set of interrelated tasks that, together, transform inputs into outputs"; in the ISO/IEC-15288:2008, the definition of "process"is that "the process is a set of interrelated or interacting activities which transforms inputs into outputs". So the definitions of "process" in the two standards have the same meaning.

After analyzing the four risks identified above, we concluded that they present no real danger for the multistandard approach and can be avoided easily. As a result, the processes from the different standards can work together very well.

\section{Conclusion}

In this paper, our research objective was to compare the SE standards strength and weaknesses and improve the coordination of systems engineering processes, in order to help project leaders to choose the mostefficient and coherent option for best achieving their targets. First of all, we reviewed the history and evolution of the SE standard, and thenanalyzed and compared the three most important: ANSI/EIA-632:1998, ISO/IEC-15288:2008 and IEEE1220:2005. Based on the understanding of the three standards, we proposed a multi-standard approach to achieve the customized standard. The resulting customized system engineering standard can cover the entire system life cycle, allows more flexibility and expandability for systems engineering and focuses more on validation and verification.But it also presented risks of incoherencebecause the different processes came from different standards. Depending on the differences between the standards, we identified four risks and discussed them.

\section{References}

American National Standards Institute (1999) 'Processes for engineering a system',pp.1-123.

Sahraoui, A. (2006)'Processes for Engineering a System an Introduction to Processes, Methods and Tools', Proceedings of the Information and Communication Technologies, Vol. 2. pp. 2760-2765.

Sharon, A., de Weck, O.L. and Dori, D. (2011)'Project management vs. systems engineering management: A practitioners' view on integrating the project and product domains', Systems Engineering, vol.14, No.4, pp 427-440.

Rao, B.S. and Sarda,N.L. (2003)'Effort drivers in maintenance outsourcing-an experiment using Taguchi’s methodology', Proceedings ofthe $7^{\text {th }}$ European Conference on Software Maintenance and Reengineering, pp.271-280.

Olson, B. A.,Mazzuchi,T. A., Sarkani, S. and Forsberg, K. (2012) ‘ Problem management process, filling the gap in the systems engineering processes between the risk and opportunity processes', Systems Engineering, Vol.15, No.3, 275-286.

Callegari,D.A. and Bastos,R.M. (2007)'Project Management and Software Development Processes: Integrating RUP and PMBOK', International Conference on Systems Engineering and Modeling, pp 1-8.

Department of Defense(1969)‘System Engineering Management’, Military STD 499. 
Department of Defense(1974)'Engineering Management', Military STD 499(A).

Department of Defense(1974) 'Engineering Management', Military STD 499(B).

Alsyouf, I. (2004)‘Cost Effective Maintenance for Competitive Advantages', PhD Thesis, Göteborg, Växjö University.

Institute of Electrical and Electronics Engineers.(1999)'Standard for Application and Management of the Systems Engineering Process', IEEE STD 1220.

Institute of Electrical and Electronics Engineers.(2005) 'Standard for Application and Management of the Systems Engineering Process', IEEE STD 1220.

Institute of Electrical and Electronics Engineers.(2002)'Standard for Systems engineering - System life cycle processes,'IEEESTD 15288.

Institute of Electrical and Electronics Engineers.(2006) 'Standard for Systems engineering - System life cycle processes',IEEE STD 15288.

Institute of Electrical and Electronics Engineers.(2008)'Standard for Systems and software engineering - System life cycle processes', IEEE STD 15288.

ISO/IEC 24748 (2010) “Systems and software engineering — Lifecycle management —Part 1:Guide for life cycle management".

ISO/IEC TR 24748 (2011) "Systems and software engineering -- Life cycle management -- Part 2: Guide to the application of ISO/IEC 15288 (System life cycle processes)"

Boarder,J.C. (1995)'The system engineering process'.Proceedings of the IEEE Annual International International, pp. 293-298.

NASA. (1995)‘NASA systems engineering handbook’, NASA-SP-6105, Houston, TX.

Roedler, G. (2002)'What is ISO/IEC 15288 and Why Should I Care, presentation slides',Geneva: International Organization for Standardization.

Singh, R. (1995) 'The Software Life Cycle Processes standard', Computer, Vol.28, No.11, pp 89-90.

Swarz, R.S. and DeRosa,J.K. (2006)‘A framework for enterprise systems engineering processes',Proceedings of theInternational Conference on Software and Systems Engineering,pp B32-1-9.

Sheard,S. andLake,J.K. (1998) 'Systems engineering standards and models compared', Proceedings of the 8th International Symposium on Systems Engineering, Vancouver, Canada,pp. 589-605.

Ricardo ,V.(2005) 'Systems Engineering: What's in a name?'IIE Annual Conference, Atlanta, GA.

Wang, Y.,King, G.,Dorling, A. and Wickberg,H. (1999) 'A unified framework for the software engineering process system standards and models', Proceedings of the 4th IEEE International Symposium and Forum on Software Engineering Standards, pp 132-144.

Conforto, E.,Rossi, M.,Rebentisch,E.,Oehmen, J. and Pacenza,M. (2013) 'Improving the integration of Program Management and System Engineering' Whitepaper presented at the 23th INCOSE Annual International Symposium, Philadelphia, USA. 
Figure 1 Evolution of systems engineering standards from 1969 to the present

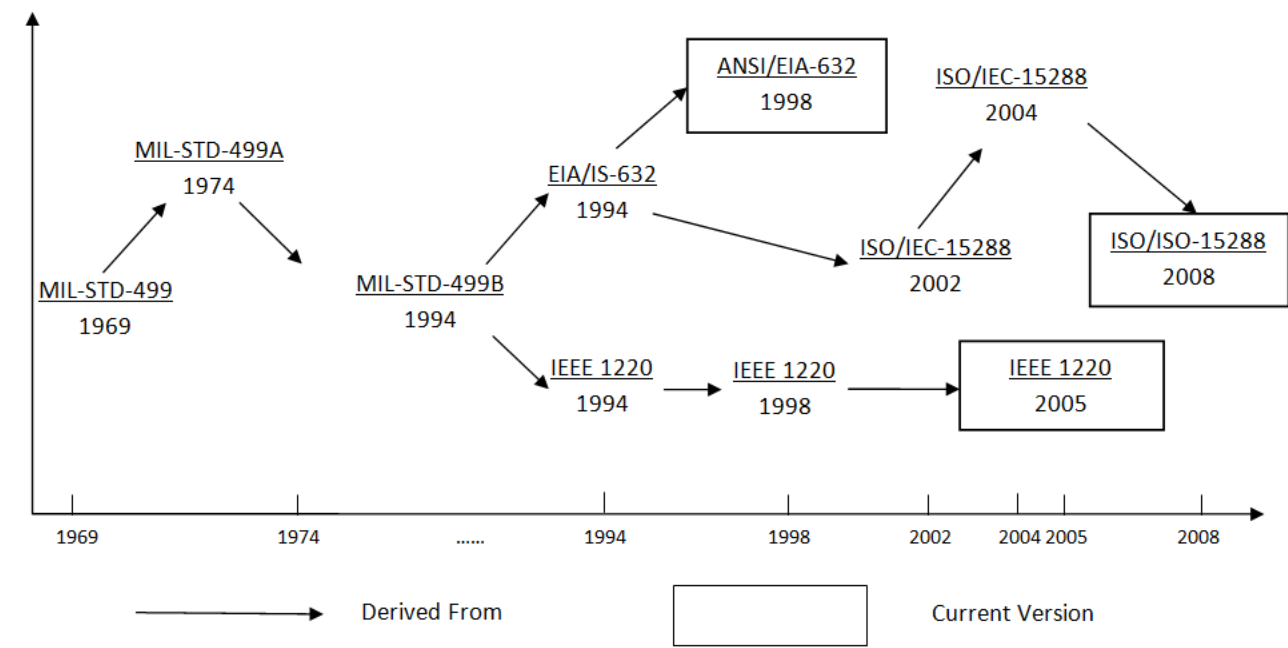

Figure 2The different system life cycles defined in the three standards

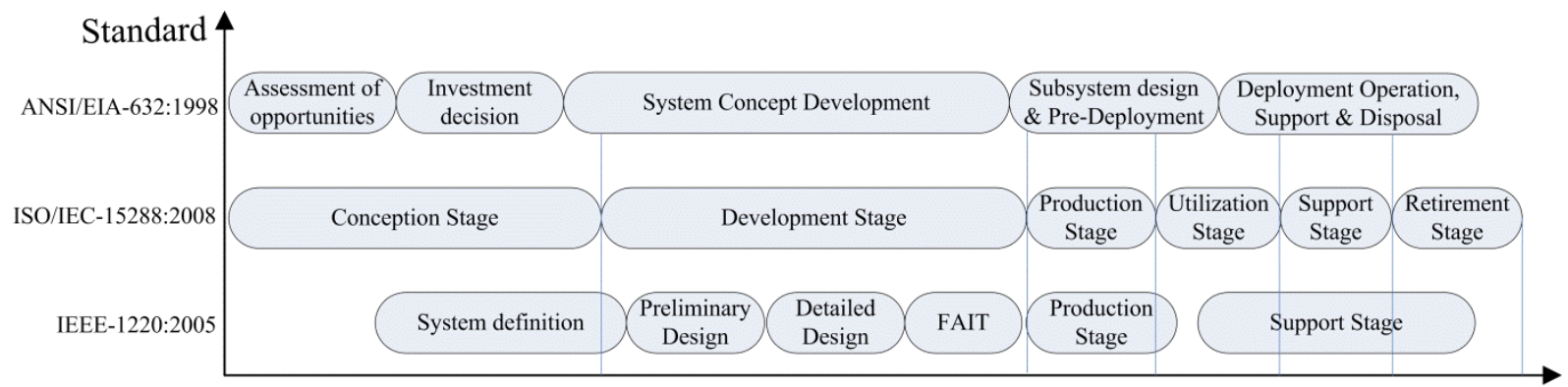

System Life Cycle

Figure 3Final systems engineering processes

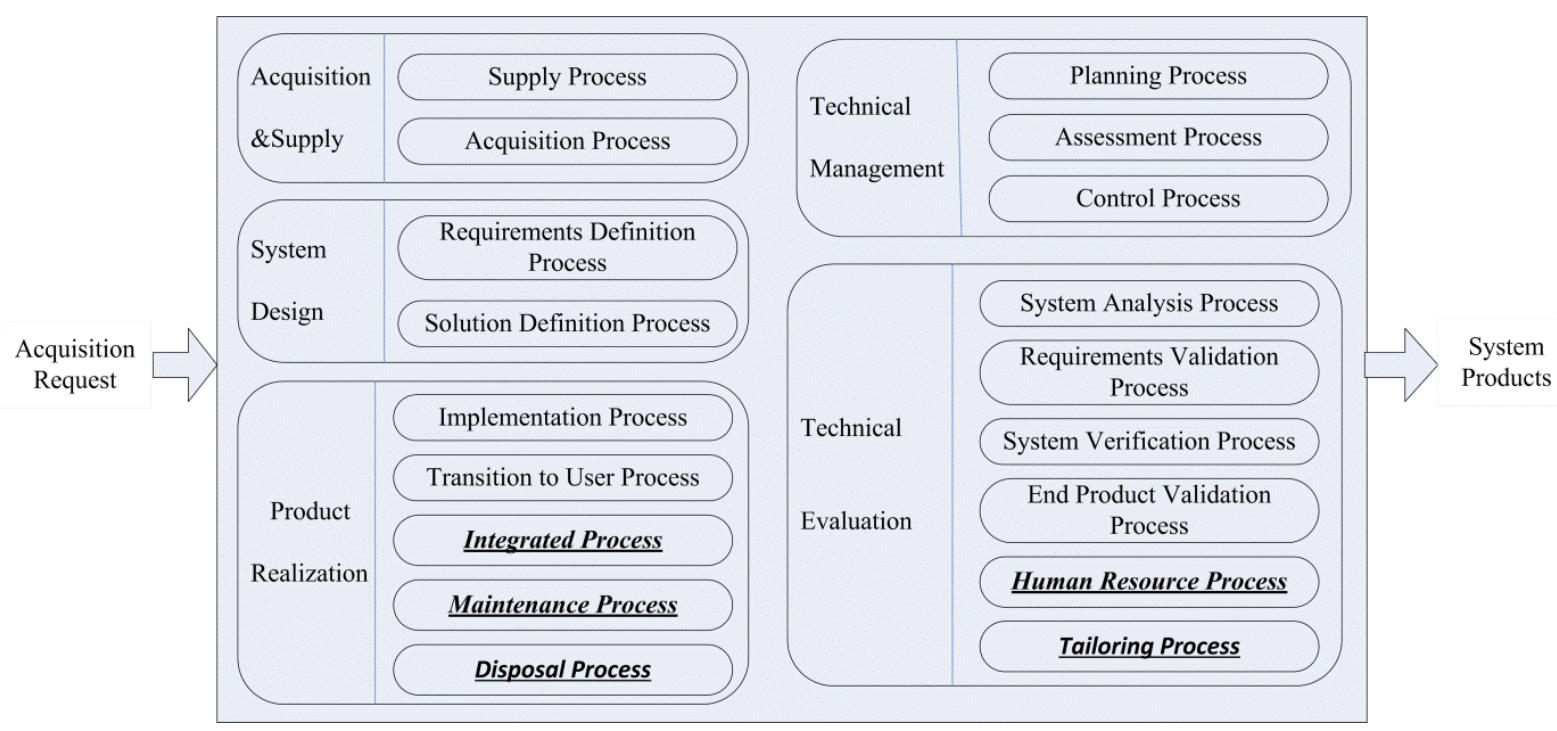

